\title{
Internal reliability, homogeneity, and factor structure of the ten-item Autism-Spectrum Quotient (AQ-10) with two additional response categories
}

\author{
Alex Bertrams \\ University of Bern, Educational Psychology Lab, Institute of Educational Science, Faculty of Human Sciences, Fabrikstrasse 8, \\ 3012 Bern, Switzerland \\ *Corresponding author: E-mail: alexander.bertrams@edu.unibe.ch
}

(Received 27 August 2020; Revised 17 December 2020; Accepted 19 December 2020)

\begin{abstract}
The ten-item short form of the Autism-Spectrum Quotient (AQ-10) has been used to efficiently assess autistic traits in the general population; however, the psychometric properties of the AQ-10 in terms of its internal reliability and its unifactorial structure have recently been questioned. In the present study $(N=$ 797), whether the internal reliability is increased when the AQ-10 is applied with six rather than the conventional four response categories has been investigated. Moreover, correlational and confirmatory factor analyses were conducted to examine the reason for potential inhomogeneity within the AQ-10. The results suggest that the internal reliability of the AQ-10 was slightly increased but is still unsatisfactory, likely due to the incompatibility of items from two subdimensions: attention to detail and imagination. With six of the AQ-10 items, crucial aspects of the autistic personality may be measured, but other important aspects would be neglected; thus, the measure requires further psychometric development.
\end{abstract}

Keywords: Autism; Autistic Traits; Measurement; Psychometrics; Questionnaire

\section{Introduction}

The autism-spectrum quotient (AQ; Baron-Cohen et al., 2001) is a questionnaire used as a screening tool for autism in psychiatric and psychological diagnostics (Huang et al., 2020; Woodbury-Smith et al., 2005). It is also applied in research to measure autistic traits in the general population (e.g., Lewton et al., 2019; Lin et al., 2020; Yaxu et al., 2020). In particular, its ten-item short form (AQ-10; Allison et al., 2012) can be an efficient measure for research purposes (e.g., Bertrams \& Schlegel, 2020; Gollwitzer et al., 2019; Lundin et al., 2019). However, recently, the AQ-10 has been demonstrated to be psychometrically insufficient (Taylor et al., 2020). Re-analysing a large sample of 6,595 participants recruited online, Taylor et al. (2020) found that the AQ-10 showed poor internal reliability defined by metrics <.70. Moreover, there was no unifactorial structure, indicating that the AQ-10 partly consists of unrelated dimensions, which explains the low internal reliability. In sum, in its current form, the AQ-10 appears to be limited in measuring autistic traits in the general population.

One aim of the present study was to examine whether a change in the response format of the AQ-10 would increase the inner consistency of the measure. Usually, the AQ-10 is answered using four-point response scales (definitely agree, slightly agree, slightly disagree, definitely disagree). Reliability and validity may be decreased with only four compared to more response categories, as greater categorization 
is associated with a greater loss of information and, in turn, a greater attenuation of the relationships between items (Lozano et al., 2008). After a literature review, Gries et al. (2018) concluded that five-point or six-point verbal rating scales are more informative and discriminative than scales with fewer response options. Therefore, in the present research, the six-point response scale was tested for the AQ-10. Due to the even number of categories, the forced choice format of the AQ-10 was maintained, and for most people in the general population, six categories should still be easily mentally processable given the frequent use of scales with more response categories in psychological research.

As another aim of the present work, correlational and confirmatory factor analyses (CFA) were applied to investigate which subdimensions/items would lower the inner consistency of the AQ-10. The AQ-10 captures five subdimensions of autistic traits, each measured with two items (Allison et al., 2012): attention to detail, attention switching, communication, imagination, and social. It can be assumed that measuring attention to detail by self-report is problematic, as people may not be aware that their so-called central coherence is lower compared to that of other people (Freitag et al., 2007). This may be why most of the respective AQ items showed insufficient psychometric properties in Freitag et al.'s (2007) study, leading to the deletion of the attention to detail subdimension in their AQ adaptation. In addition, one of the two attention to detail items had no substantial loading on any factor in Taylor et al.'s (2020) reanalysis. Furthermore, the AQ-10 item "I like to collect information about categories of things (e.g. types of car, types of bird, types of train, types of plant, etc.)" from the subdimension imagination has an obvious lack of content validity. Unsurprisingly, this item did not load on any of the factors in Taylor et al.'s (2020) study. Thus, it was expected that the attention to detail and imagination subdimensions would not fit well with the remaining subdimensions of the AQ-10. Based on the recent merging of the social communication and social interaction areas in the Diagnostic and Statistical Manual of Mental Disorders (American Psychiatric Association, 2013), an additional CFA model was tested in which the subdimensions communication and social were combined into one common factor.

\section{Methods}

The initial sample consisted of 1,025 individuals from the United States recruited from the Mechanical Turk platform. Due to a failed attention check, 149 individuals were excluded from the analyses. As the present study involved measuring autistic traits in the general population, the data of another 79 individuals who indicated they had an autism diagnosis or were not sure about it were excluded (auxiliary analyses showed that the results remained the same when these data were included). Thus, the final sample included 797 participants (52\% male, $48 \%$ female; range of age: $18-89$ years).

After giving their informed consent, the participants provided sociodemographic data (details are available from the author). This was followed by an attention check measure (Bertrams \& Schlegel, 2020): The question "Who was the first president of the United States of America?" was combined with the instruction not to check any of the three response options (Abraham Lincoln, George Washington, Thomas Jefferson), but to click "continue" instead.

Next, the participants completed the AQ-10 (Allison et al., 2012) with the alternative six-point response format. Between the conventional response categories "slightly agree" and "definitely agree," the intermediate category "agree" was inserted, and analogously, "disagree" was placed between "slightly disagree" and "definitely disagree." All responses were coded with values from 1 to 6, with higher numbers always indicating a more autistic characteristic (e.g., higher values on the subdimension imagination actually reflect a relative lack of imagination). After the AQ-10, the participants were thanked and debriefed, and they received US $\$ 0.25$ for participation.

\section{Results}

With the present six-point response scales, the internal reliability and homogeneity of the AQ-10 (McDonald's $\omega=.65$, Cronbach's $\alpha=.59$, Gutmann's $\lambda 6=.70$, average interitem correlation $=.13$ ) was 
slightly higher than in Taylor et al.'s (2020) study with four-point response scales (McDonald's $\omega=.58$, Cronbach's $\alpha=.50$, Gutmann's $\lambda 6=.58$, average interitem correlation $=.11$ ).

As shown in Table 1, the attention to detail subdimension did not correlate with any of the other AQ-10 subdimensions ( $p s>.12$ ). The subdimension imagination weakly negatively correlated with the subdimension attention switching and positively with the subdimension social, and it was uncorrelated with the other two subdimensions ( $p s>.12$ ). The other three subdimensions (attention switching, communication, and social) were intercorrelated.

Table 2 and Figure 1 present the models and the results of the model tests from the CFAs. As can be observed, all models involving the subdimensions attention to detail and imagination failed to provide an acceptable fit. The two models without these two subdimensions and with a second-order factor (models 6 and 7) fit best. With only the six items of models 6 and 7, the internal reliability and

Table 1. Means, Standard Deviations, and Correlations.

\begin{tabular}{|c|c|c|c|c|c|c|c|c|}
\hline \multirow[b]{2}{*}{ AQ-10 } & \multirow[b]{2}{*}{$M$} & \multirow[b]{2}{*}{$S D$} & \multicolumn{6}{|c|}{ Correlations } \\
\hline & & & Total & AtD & AS & $C$ & 1 & $S$ \\
\hline Total & 3.04 & 0.56 & - & & & & & \\
\hline AtD & 3.41 & 0.80 & $.33^{* \star *}$ & - & & & & \\
\hline AS & 2.96 & 1.03 & $.62^{\star \star \star}$ & .03 & - & & & \\
\hline C & 2.66 & 0.96 & $.70^{\star \star \star \star}$ & .03 & $.49^{\star \star \star \star}$ & - & & \\
\hline 1 & 3.17 & 1.07 & $.48^{* * *}$ & .05 & $-.07^{\star}$ & .01 & - & \\
\hline S & 2.98 & 0.95 & $.75^{\star \star \star}$ & .02 & $.31^{\star \star \star *}$ & $.49^{\star \star \star *}$ & $.32^{\text {***}}$ & - \\
\hline C\&S & 2.82 & 0.82 & $.84^{\star \star \star *}$ & .03 & $.46^{\star \star * *}$ & $.87^{\star \star * *}$ & $.19^{* \star \star}$ & $.86^{\star * *}$ \\
\hline
\end{tabular}

Note. $N=797$. Overall scores of the $\mathrm{AQ}-10$ and the AQ-10 subdimensions were obtained by averaging the responses to the items of the scale/subdimensions. Total $=\mathrm{AQ}-10$ total score $(10 \mathrm{items}) . A \mathrm{At}=$ the subdimension attention to detail, $\mathrm{AS}=$ the subdimension attention switching, $\mathrm{C}=$ the subdimension communication, $\mathrm{I}=$ the subdimension imagination, $\mathrm{S}=$ the subdimension social, $\mathrm{C} \& \mathrm{~S}=$ the subdimensions communication and social combined into one common factor.

${ }^{*} p<.05$.

${ }^{* *} p<.01$.

${ }_{\star \star * \star} p<.001$

Table 2. Confirmatory Factor Analyses.

\begin{tabular}{llll}
\hline & & \multicolumn{2}{l}{ Model fit } \\
\cline { 2 - 4 } Model & SRMR & CFI & $\chi^{2}$ \\
\hline 1) Ten items - unifactorial (AT) & .20 & .60 & $272.90, p<.001$ \\
\hline 2) Ten items - five first-order factors (AtD, AS, C, I, S), one S-O & .18 & .69 & $211.47, p<.001$ \\
\hline 3) Eight items (without AtD) - unifactorial (AT) & .20 & .61 & $247.18, p<.001$ \\
\hline 4) Eight items (without AtD) - four first-order factors (AS, C, I, S), one S-O & .18 & .72 & $181.96, p<.001$ \\
\hline 5) Six items (without AtD and I) - unifactorial (AT) & .07 & .82 & $55.36, p<.001$ \\
\hline 6) Six items (without AtD and I) - three first-order factors (AS, C, S), one S-O & .03 & .96 & $16.77, p=.01$ \\
\hline 7) Six items (without AtD and I) - two first-order factors (AS, C\&S), one S-O & .03 & .96 & $18.82, p=.01$ \\
\hline
\end{tabular}

Note. $N=797$. The robust weighted least squares estimation was applied. The standardized root mean square residual (SRMR) and the comparative fit index (CFI) were used to evaluate the model fit (Hu \& Bentler, 1998). AT=all items in one common autistic traits factor, $\mathrm{S}-\mathrm{O}=$ second-order factor for all involved first-order factors, AtD = the subdimension attention to detail, AS=the subdimension attention switching, $\mathrm{C}=$ the subdimension communication, $\mathrm{I}=$ the subdimension imagination, $\mathrm{S}=$ the subdimension social, $\mathrm{C} \& \mathrm{~S}=$ the subdimensions communication and social combined into one common factor. 
Model 1

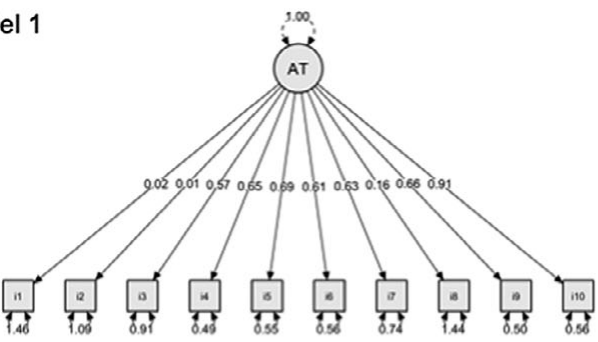

Model 3

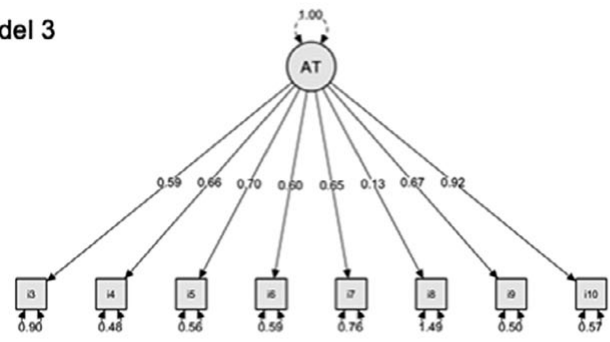

Model 5

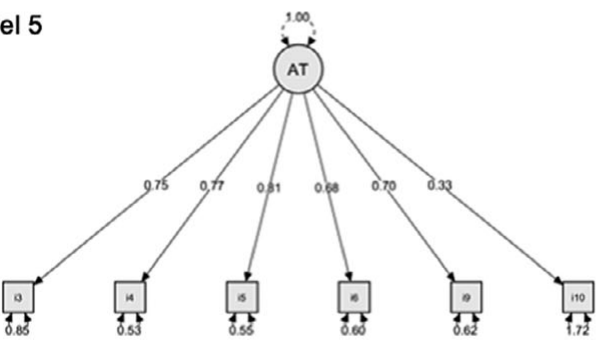

Model 2

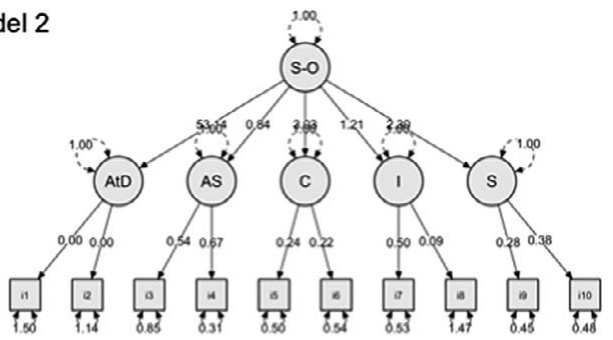

Model 4

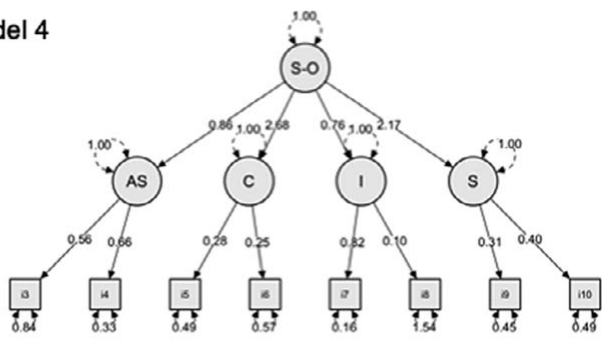

Model 6

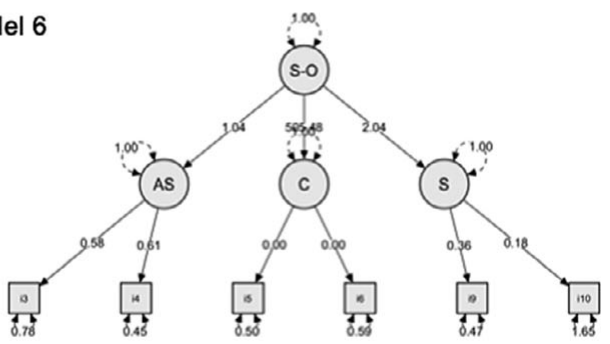

Model 7

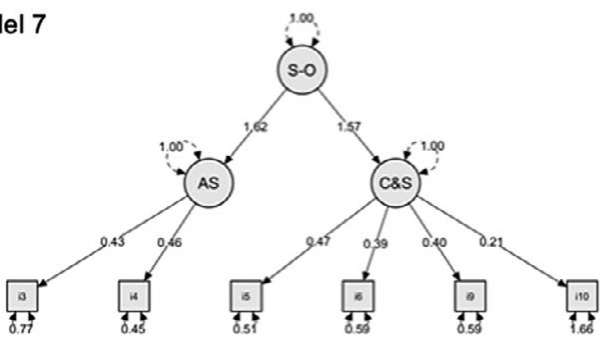

Figure 1. Illustration of the seven models tested by confirmatory factor analyses and the estimates obtained. AT = all items in one common autistic traits factor, $\mathrm{S}-\mathrm{O}=$ second order factor for all involved first-order factors, AtD=the subdimension attention to detail, $\mathrm{AS}=$ the subdimension attention switching, $\mathrm{C}=$ the subdimension communication, $\mathrm{I}=$ the subdimension imagination, $\mathrm{S}=$ the subdimension social, $\mathrm{C} \& \mathrm{~S}=$ the subdimensions communication and social combined into one common factor. $N=797$.

homogeneity were as follows: McDonald's $\omega=.77$, Cronbach's $\alpha=.74$, Gutmann's $\lambda 6=.75$, average interitem correlation $=.34$.

\section{Discussion}

The present study showed that the AQ-10 with six-point rather than four-point response scales gained somewhat more internal consistency and homogeneity. However, overall, the parameters were still unsatisfactory with McDonald's $\omega$ and Cronbach's $\alpha<.70$ (Taylor et al., 2020) and the average interitem correlation was $<.20$ (Briggs \& Cheek, 1986). 
Furthermore, as the intercorrelations of the subdimensions implied, no acceptable model fit was achieved when the subdimensions attention to detail and imagination were included in the CFAs. Freitag et al. (2007) argued that people may not be able to perceive or report on their attention to detail or neglect of context, respectively. Regarding imagination, one of the two items in the AQ-10 seems poorly chosen. As mentioned in the introduction, the item is not directly related to imagination-the occurrence of a reality-based hobby (collecting information about categories of things) does not allow for concluding that there is a lack of imaginative ability or motivation. With only one item left, no imagination factor could be further examined.

The six items of the AQ-10 subdimensions attention switching, communication, and social fit adequality together under the umbrella of autistic traits. Together, they also demonstrated sufficient internal reliability and homogeneity (at least, in combination with six-point response scales). These six items might therefore be used to selectively measure crucial aspects of autistic personality in the general population. However, when used as an "AQ-6" in the future, other important aspects would be neglected (e.g., adherence to routines, hyper- or hyporeactivity to sensory input). As an aspect of construct validity, it is also yet unclear whether such a shortened scale would measure autism. Thus, it is desirable to find appropriate complementary items for the efficient measurement of autistic traits and examine the validity of the newly developed instrument. In contrast to the empirically guided item selection procedure for the AQ-10 (Allison et al., 2012), theoretical considerations should be included.

Author Contributions. AB conceived and designed the study, conducted the data gathering, performed the statistical analyses, and wrote the article.

Funding Information. This work was supported by a grant from the Uranus Foundation.

Conflicts of Interest. The author declares no conflicts of interest.

Ethics Statement. The author asserts that all procedures contributing to this work comply with the ethical standards of the relevant national and institutional committees on human experimentation and with the Helsinki Declaration of 1975, as revised in 2008 .

Data Availability Statement. The dataset generated for this study is available on request from the author.

\section{References}

Allison, C., Auyeung, B., \& Baron-Cohen, S. (2012). Toward brief "red flags" for autism screening: The short autism spectrum quotient and the short quantitative checklist in 1,000 cases and 3,000 controls. Journal of the American Academy of Child and Adolescent Psychiatry, 51, 202-212.e7. doi: https://doi.org/10.1016/j.jaac.2011.11.003.

American Psychiatric Association (2013). Diagnostic and statistical manual for mental disorders (DSM-5, 5th ed.). American Psychiatric Publishing.

Baron-Cohen, S., Wheelwright, S., Skinner, R., Martin, J., \& Clubley, E. (2001). The autism-spectrum quotient (AQ): Evidence from Asperger syndrome/high-functioning autism, males and females, scientists and mathematicians. Journal of Autism and Developmental Disorders, 31, 5-17. doi: https://doi.org/10.1023/A:1005653411471.

Bertrams, A., \& Schlegel, K. (2020). Speeded reasoning moderates the inverse relationship between autistic traits and emotion recognition. Autism, 24, 2304-2309. doi: https://doi.org/10.1177/1362361320937090.

Briggs, S. R., \& Cheek, J. M. (1986). The role of factor analysis in the development and evaluation of personality scales. Journal of Personality, 54, 106-148. doi: https://doi.org/10.1111/j.1467-6494.1986.tb00391.x.

Freitag, C. M., Retz-Junginger, P., Retz, W., Seitz, C., Palmason, H., Meyer, J., Meyer, J., Rösler, M., \& von Gontard, A. (2007). Evaluation der deutschen Version des Autismus-Spektrum-Quotienten (AQ) - die Kurzversion AQ-k [German adaptation of the Autism-Spectrum Quotient (AQ): Evaluation and short version AQ-k]. Zeitschrift für Klinische Psychologie und Psychotherapie, 36, 280-289. doi: https://doi.org/10.1026/1616-3443.36.4.280.

Gollwitzer, A., Martel, C., McPartland, J. C., \& Bargh, J. A. (2019). Autism spectrum traits predict higher social psychological skill. Proceedings of the National Academy of Sciences of the United States of America, 116, 19245-19247. doi: https://doi.org/ 10.1073/pnas.1911460116.

Gries, K., Berry, P., Harrington, M., Crescioni, M., Patel, M., Rudell, K., Safikhani, S., Pease, S., \& Vernon, M. (2018). Literature review to assemble the evidence for response scales used in patient-reported outcome measures. Journal of PatientReported Outcomes, 2, 41. doi: https://doi.org/10.1186/s41687-018-0056-3.

Hu, L., \& Bentler, P. M. (1998). Fit indices in covariance structure modeling: Sensitivity to underparameterized model misspecification. Psychological Methods, 3, 424-453. doi: https://doi.org/10.1037/1082-989X.3.4.424. 
Huang, Y., Arnold, S. R. C., Foley, K.-R., \& Trollor, J. N. (2020). Diagnosis of autism in adulthood: A scoping review. Autism, 24, 1311-1327. doi: https://doi.org/10.1177/1362361320903128.

Lewton, M., Ashwin, C., \& Brosnan, M. (2019). Syllogistic reasoning reveals reduced bias in people with higher autistic-like traits from the general population. Autism, 23, 1311-1321. doi: https://doi.org/10.1177/1362361318808779.

Lin, G., Cui, Y., Zeng, J., \& Huang, L. (2020). The effect of autistic traits on social orienting in typically developing individuals. Frontiers in Psychology, 11, 794. doi: http://doi.org/10.3389/fpsyg.2020.00794.

Lozano, L. M., García-Cueto, E., \& Muñiz, J. (2008). Effect of the number of response categories on the reliability and validity of rating scales. Methodology, 4, 73-79. doi: https://doi.org/10.1027/1614-2241.4.2.73.

Lundin, A., Kosidou, K., \& Dalman, C. (2019). Measuring autism traits in the adult general population with the brief AutismSpectrum Quotient, AQ-10: Findings from the Stockholm Public Health Cohort. Journal of Autism and Developmental Disorders, 49, 773-780. doi: https://doi.org/10.1007/s10803-018-3749-9.

Taylor, E., Livingston, L., Clutterbuck, R., \& Shah, P. (2020). Psychometric concerns with the 10-item Autism-Spectrum Quotient (AQ10) as a measure of trait autism in the general population. Experimental Results, 1, [e3]. doi: https://doi.org/ 10.1017/exp.2019.3.

Woodbury-Smith, M. R., Robinson, J., Wheelwright, S., \& Baron-Cohen, S. (2005). Screening adults for Asperger Syndrome using the AQ: A preliminary study of its diagnostic validity in clinical practice. Journal of Autism and Developmental Disorders, 35, 331-335. doi: https://doi.org/10.1007/s10803-005-3300-7.

Yaxu, Y., Ren, Z., Ward, J., \& Jiang, Q. (2020). Atypical brain structures as a function of gray matter volume (GMV) and gray matter density (GMD) in young adults relating to autism spectrum traits. Frontiers in Psychology, 11, 523. doi: https://doi.org/ 10.3389/fpsyg.2020.00523.

Cite this article: Bertrams A (2020). Internal reliability, homogeneity, and factor structure of the ten-item Autism-Spectrum Quotient (AQ-10) with two additional response categories Experimental Results, 2, e3, 1-9. https://doi.org/10.1017/exp.2020.70 


\title{
Peer Reviews
}

\author{
Reviewing editor: Dr. Punit Shah
}

University of Bath, Department of Psychology, Bath, United Kingdom of Great Britain and Northern Ireland, BA2 7AY

This article has been accepted because it is deemed to be scientifically sound, has the correct controls, has appropriate methodology and is statistically valid, and met required revisions.

doi:10.1017/exp.2020.70.pr1

Review 1: Internal reliability, homogeneity, and factor structure of the ten-item Autism-Spectrum Quotient (AQ-10) with two additional response categories

Reviewer: Ms. Emily C Taylor (D)

University of Bath, Department of Psychology, Bath, United Kingdom of Great Britain and Northern Ireland

Date of review: 03 September 2020

(c) The Author(s), 2020. Published by Cambridge University Press. This is an Open Access article, distributed under the terms of
the Creative Commons Attribution licence (http://creativecommons.org/licenses/by/4.0/), which permits unrestricted re-use,
distribution, and reproduction in any medium, provided the original work is properly cited.

Conflict of interest statement. Reviewer declares none.

Comments to the Author: This is a valuable contribution to the literature, outlining how autism trait measures may be improved in light of recent psychometric concerns. The paper is concise and well written. However, a few additions could be included. First, the authors could comment on whether the pattern of results are the same with the diagnosed/unsure participants included. By excluding such participants, the variance of autistic traits in the sample was greatly reduced. When using AQ measures for research in the general population, diagnosis is not often screened for. Therefore, it is important to consider the psychometric properties of the measure with such individuals included, as this will more likely represent the use of the AQ in the research context described by the authors (i.e., autistic traits measured in the general population). If the pattern of results is different, this could be reported as a supplementary analysis. In line with this, it would be helpful to include some brief descriptive statistics as an indication of the AQ variance within the sample. Finally, while the authors identify 6 items that together have good psychometric properties, whether they measure autism is unclear (i.e. the construct validity). A comment should be included emphasising this.

\section{Score Card}

Presentation

Is the article written in clear and proper English? (30\%)

Is the data presented in the most useful manner? (40\%)

Does the paper cite relevant and related articles appropriately? (30\%) 
Does the abstract correctly embody the content of the article? (25\%)

Does the introduction give appropriate context? (25\%)

Is the objective of the experiment clearly defined? $(25 \%)$

Analysis

Does the discussion adequately interpret the results presented? (40\%)

Is the conclusion consistent with the results and discussion? (40\%)

Are the limitations of the experiment as well as the contributions of the experiment clearly outlined? (20\%) 


\title{
Review 2: Internal reliability, homogeneity, and factor structure of the ten-item Autism-
} Spectrum Quotient (AQ-10) with two additional response categories

\author{
Reviewer: Dr. George Farmer
}

University of Cambridge, Faculty of Mathematics, Cambridge, United Kingdom of Great Britain and Northern Ireland

Date of review: 12 December 2020

\begin{abstract}
(C) The Author(s), 2020. Published by Cambridge University Press. This is an Open Access article, distributed under the terms of the Creative Commons Attribution licence (http://creativecommons.org/licenses/by/4.0/), which permits unrestricted re-use, distribution, and reproduction in any medium, provided the original work is properly cited.
\end{abstract}

Conflict of interest statement. Reviewer declares none.

Comments to the Author: The paper reports issues with the reliability of the AQ10 measure of autistic traits. This is a useful replication of Taylor et al's larger $\mathrm{n}$ study. It additionally establishes that increasing the number of response categories does not resolve these issues. This work should be useful for researchers looking to use the AQ in an abbreviated form.

The logic behind additional response categories potentially improving the reliability is not made clear. As that it is the main contribution of this work, it might be useful to provide a little more detail. It might also be useful to explain the attention check procedure used on mTurk to reassure the reader that this isn't selecting people with greater attention to detail.

\section{Score Card}

Presentation

Is the data presented in the most useful manner? (40\%)

Does the paper cite relevant and related articles appropriately? (30\%)

\section{Context}

Does the abstract correctly embody the content of the article? (25\%)

Does the introduction give appropriate context? (25\%)

Is the objective of the experiment clearly defined? (25\%)

Are the limitations of the experiment as well as the contributions of the experiment clearly outlined? (20\%) 